\title{
The Mountain Pine Beetle Epidemic in the Black Hills, South Dakota: The Consequences of Long Term Fire Policy, Climate Change and the Use of Remote Sensing to Enhance Mitigation
}

\author{
Kyle Mullen ${ }^{1}$, Fei Yuan ${ }^{2} \&$ Martin Mitchell $^{2}$ \\ ${ }^{1}$ Bolton \& Menk, Inc., 1960 Premier Drive, Mankato, MN 56001, USA \\ ${ }^{2}$ Geography Department, Minnesota State University, Mankato, MN 56001, USA \\ Correspondence: Martin Mitchell, Professor, Geography Department, Minnesota State University, Mankato, MN \\ 56001, USA. Tel: 1-507-389-1610. E-mail: martin.mitchell@mnsu.edu
}

Received: November 23, 2017

doi:10.5539/jgg.v10n1p69
Accepted: December 8, 2017 Online Published: January 7, 2018

URL: http://dx.doi.org/10.5539/jgg.v10n1p69

\begin{abstract}
The recent and intense outbreak (first decade of 2000s) of the mountain pine beetle in the Black Hills of South Dakota and Wyoming, which impacted over 33\% of the 1.2 million acre $(486,000$ ha) Black Hills National Forest, illustrates what can occur when forest management practices intersect with natural climatic oscillations and climate change to create the "perfect storm" in a region where the physical environment sets the stage for a plethora of economic activities ranging from extractive industries to tourism. This study evaluates the potential of WorldView-2 satellite imagery for green-attacked tree detection in the ponderosa pine forest of the Black Hills, USA. It also discusses the consequences of long term fire policy and climate change, and the use of remote sensing technology to enhance mitigation. It was found that the near-infrared one (band 7) of WorldView-2 imagery had the highest influence on the green-attack classification. The Random Forest classification produced the best results when transferred to the independent dataset, whereas the Logistic Regression models consistently yielded the highest accuracies when cross-validated with the training data. Lessons learned include: (1) utilizing recent advances in remote sensing technologies, most notably the use of WorldView-2 data, to assist in more effectively implementing mitigation measures during an epidemic, and (2) implementing pre-emptive thinning strategies; both of which can be applied elsewhere in the American West to more effectively blunt or preclude the consequences of a mountain pine beetle outbreak on an existing ponderosa pine forest.
\end{abstract}

Keywords: Black Hills, mountain pine beetle, climate change, remote sensing, ponderosa pine fire policy and forest management

\section{Introduction}

\subsection{The Mountain Pine Beetle}

Native to the Black Hills, the mountain pine beetle (Dendroctonus ponderosae), commonly referred to as the bark beetle, ranges from Mexico to British Columbia. Mountain pine beetles take flight in July and August and subsequently bore into trees and construct vertical egg galleries (Safranik and Carroll 2006). After overwintering, the larvae feed on nutrients in the phloem where they construct feeding tunnels perpendicular to the egg galleries. By late spring the larvae pupate and metamorphose in early summer. Subsequently, adults fly to another host tree in the vicinity, usually within about 100 feet $(30 \mathrm{~m})$ and then the cycle repeats (Bentz et al. $1991 \&$ Leatherman et al. 2007). Ponderosa pines respond to a beetle attack by transporting sap to beetle entry points to "pitch" beetles out of the tree, which results in a light-colored circular plug manifesting on the surface of the darker bark (Figure 1). However, the ability of trees to "pitch" beetles is reduced during large number attacks as beetles are coated with blue stain fungus that once deposited inside the tree, inhibits internal water flow and compromises the tree's ability to cast out the beetle (Ballard et al 1984). Consequently, higher ponderosa pine mortality rates ensue.

During the early stages of a successful attack, the canopies of infected stands often appear normal even though the trunks will show the effects of pitching the beetles, as with the tree depicted in Figure 1. Identifying stands in this "green-attack" stage is very laborious and not practical in a mountainous setting with its steep terrain and extensive acreages. Referred to as the "red-attack" stage, the infected tree's canopy becomes easily identified as 
the needles eventually turn red when photosynthetic green pigments break-down and tree slowly dies. Finally, the needles drop and one encounters the "gray-attack" stage with the tree stands appearing much as they would after a severe crown fire. The snags or dead trees are then prone to blow-downs during storm events and comprise a major safety impact on over 14,000 miles $(22,500 \mathrm{~km})$ of roads and trails within the National Forests of the American West (U.S. Forest Service 2010). In addition, the fire hazard becomes accentuated because ignition temperatures drop relative to healthy trees. Overall, the U.S. Forest Service estimates that over 50 million acres of forest in the western United States have been impacted by pine beetles since 1997 (U.S. Dept. Agriculture 2016).

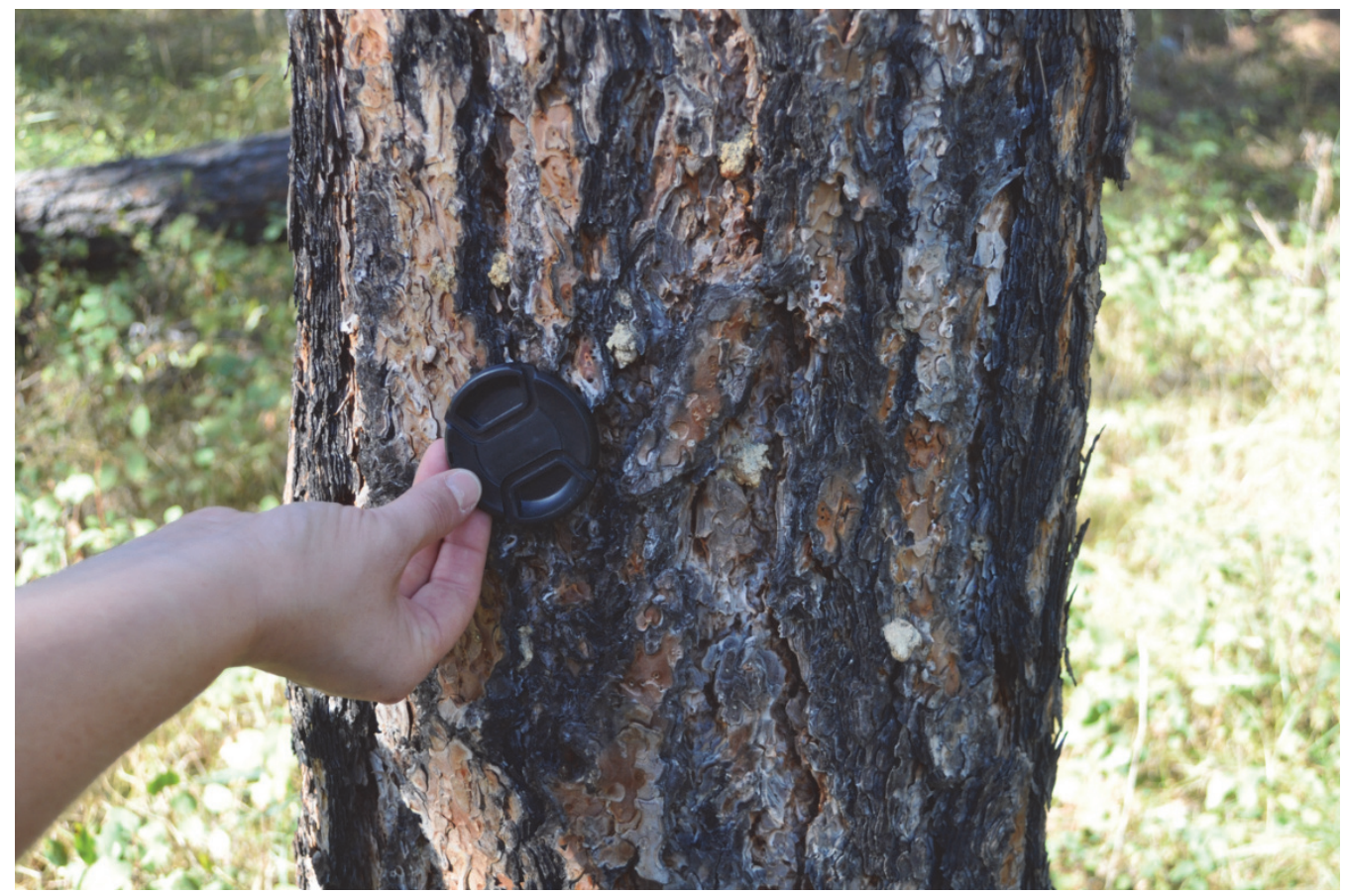

Figure 1. Ponderosa pine pitching beetles (Photo by Martin Mitchell)

Mountain pine beetle populations exist in either an endemic, incipient-epidemic, epidemic, or post-epidemic state (Safranyik and Carroll 2006). Characterized by low populations, the endemic stage exhibits damage limited to small patches of host trees and can improve forest health because the beetles remove weaker trees thereby limiting competition for water between individual trees (Wulder et al 2006 \& Safranyik and Carroll 2006). When the forest experiences multiple years of drought, warmer temperatures, and/or enhanced tree competition derived from abnormally high stand densities, the beetle population grows to an incipient-epidemic level wherein the beetles successfully attack clusters of larger diameter trees (Wulder et al. 2006 \& Safranyik and Carroll 2006). As beetle populations further increase 2 to 8 -fold, mass attacks of healthy, large-diameter stands of pines ensue, characterizing the epidemic state, resulting in the devastation of whole swathes of forest (Safranyik and Carroll 2006). Populations enter a post-epidemic stage as mortality thresholds are reached, resulting in populations and tree attacks similar to those at endemic state levels (Safranyik and Carroll 2006).

\subsection{Forest Management}

The extensive ponderosa pine forest within the Black Hills has been subjected to nearly 100 years of fire suppression starting circa 1890 and remaining dominant through much of the 20th century (Mitchell 2002; Mitchell and Yuan 2010). The heliophytic ponderosa pine forest normally incurs three to five ground fires per century, which lowered the risk of wildfires and reduced the competition for scarce water resources during drought cycles by eliminating accumulations of fuel and reducing stand densities (Brown and Seig 1996; Mitchell and Yuan 2010). Instead, long-term fire suppression policies have resulted in opposite conditions as exhibited in Figure 2a, where stand densities with mean diameters at breast height $>10$ inches $/ 25 \mathrm{~cm}$ exceeding 120 sq. ft. of basal area per acre ( 28 sq. m per ha) became common. Consequently, plant stress during drought cycles becomes amplified making the forest ripe for epidemic infestation and/or wildfire. (Mitchell and Yuan 2010; Schmid and Mata 1992 and 2005). Although recent attempts to thin the forest by means of prescribed 
burns and/or mechanical thinning to achieve basal stand densities below the 100 sq. feet/acre threshold $(23 \mathrm{sq} . \mathrm{m}$ per ha), have protected certain stands such as the one depicted in Figure $2 b$, this strategy proved, too little too late, once the beetle outbreak entered the epidemic phase.

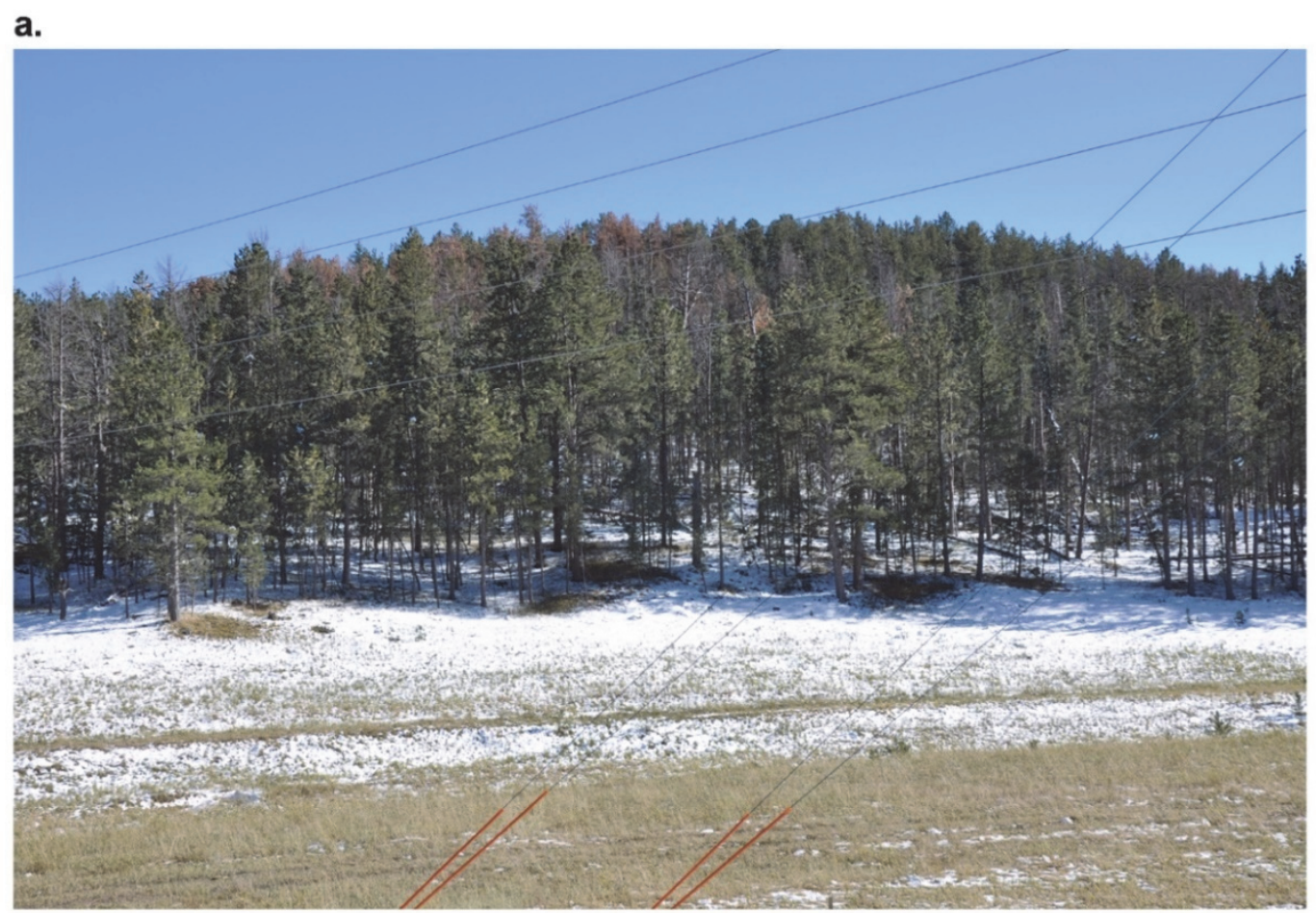

b.

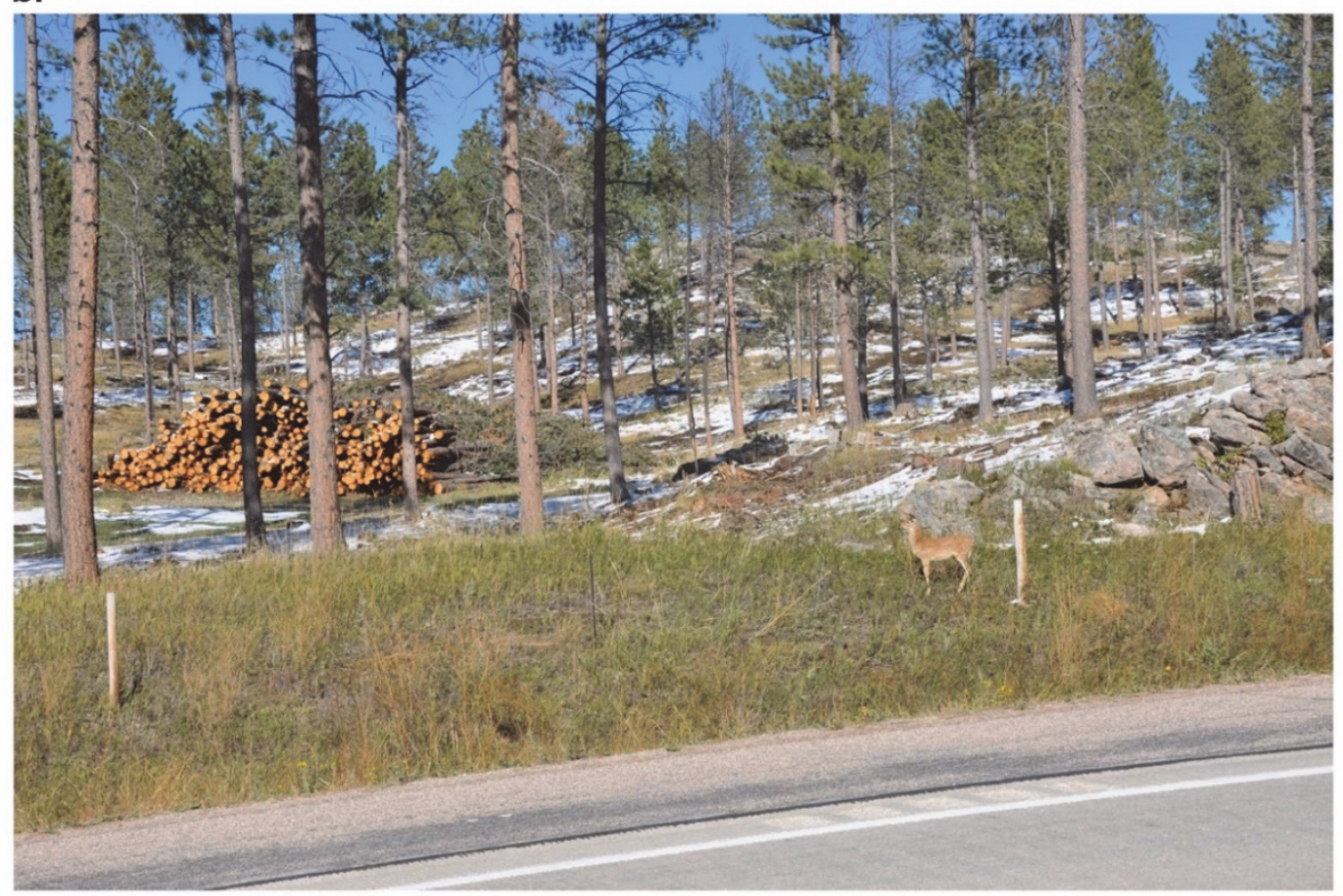

Figure 2. Dense stand of ponderosa pine with infected trees (a) and thinned stand of ponderosa pine (b) (Photos by Martin Mitchell)

\subsection{Climate Change: Less Severe Winters}

Cold wintertime temperatures comprise a factor in limiting mountain pine beetles with temperature mortality 
thresholds varying from $0^{\circ} \mathrm{F}$ to $-40^{\circ} \mathrm{F}\left(-18^{\circ} \mathrm{C}\right.$ to $\left.-40^{\circ} \mathrm{C}\right)$ dependent on the over-winter larval stage (Safranyik and Carroll 2006). In the Black Hills, December and January temperatures below $-20^{\circ} \mathrm{F}\left(-29^{\circ} \mathrm{C}\right)$ result in large-scale deaths of pine beetles (Brundige 2011). As noted in Table 1, the Black Hills experienced a greater incidence of $-20^{\circ} \mathrm{F} / 29^{\circ} \mathrm{C}$ days prior to 1985 , while a decreased amount or outright paucity, has been the norm for the past 30 years. In the southern Black Hills as exemplified by Custer, S.D. $-20^{\circ} \mathrm{F} /-29^{\circ} \mathrm{C}$ days occurred about 2 years apart from 1943 through 1984. Starting in 1985, this interval increased to almost eight years for December with a total absence of $-20^{\circ} \mathrm{F}$ days occurring for January from $1985-2016$. In the central Black Hills, $-20^{\circ} \mathrm{F} / 29^{\circ} \mathrm{C}$ days prior to 1985 occurred at Mt Rushmore about every 12 years. Starting in 1985, none have occurred at Mt Rushmore. Finally, within the northern Black Hills as exhibited by Lead, S.D. with 1985 serving as the temporal divide, the gaps between $-20^{\circ} \mathrm{F}$ days increased from 6 to 10 years in December and from 4 years to 16 years for January.

Table 1. Climate data from Western Regional Climate Center depicting the length between relative frequencies of $-20^{\circ} \mathrm{F}\left(-29^{\circ} \mathrm{C}\right)$ events in the Black Hills of South Dakota

\begin{tabular}{llll}
\hline Location & Years & Number of Years Between $\mathbf{- 2 0}^{\circ} \mathbf{F} / \mathbf{- 2 9}^{\circ} \mathbf{C}$ Temps \\
\hline Custer & & December & January \\
& $1943-1984$ & 1.9 & 1.9 \\
& $1985-2016$ & 7.8 & 31.0 \\
\hline \multirow{2}{*}{ Mt. Rushmore } & $1962-1984$ & 7.7 & 11.5 \\
& $1985-2016$ & 15.5 & 31.0 \\
\hline Lead & $1910-1984$ & 5.8 & 3.8 \\
& $1985-2016$ & 10.3 & 16.0 \\
\hline Pactola Dam & $1956-1984$ & 4.1 & 2.2 \\
& $1985-2016$ & 5.2 & 10.5 \\
\hline
\end{tabular}

\subsection{Recent Infestation (2000-2010) in Black Hills and Mitigation Measures during the Recent Epidemic}

Although the Black Hills have experienced earlier beetle epidemic events from 1895-1908 and 1968-1981 with minor outbreaks in 1936-1944 and 1963-66, the current infestation proved especially severe with widespread damage exceeding 400,000 acres or 162,000 ha (Graham et al. 2016). As the Black Hills entered into a drought cycle during the first decade of 2000s, the high stand densities wrought by the long-term effects of fire suppression, the mountain pine beetle experienced an environmental scenario favorable for a major outbreak. Moreover, the one natural variable that in earlier decades would have retarded or perhaps terminated an outbreak and its consequent damage, namely December and January temperatures dropping to below $-20^{\circ} \mathrm{F} /-29^{\circ} \mathrm{C}$, essentially ceased. As a result, extensive swathes of ponderosa pine and even some white spruce stands near Harney Peak became devastated. When abnormally high precipitation totals returned during this decade (2010s), the outbreak entered a post-epidemic state.

One mode of mitigation is to spray the tree with an insecticide. However, the whole tree must be sprayed not merely the lower trunk. Although effective, this method proves expensive because of its high reliance on costly chemicals and intensive amounts of manual labor. Consequently, insecticide applications are suitable only for stands prone to high visibility in tourist areas such as those at Mt Rushmore (Auchtenburg, 2013). Indeed, the National Park Service implemented this treatment along the walkways at Mt. Rushmore, where close to 3 million visitors pass every year.

Another more common and practical mitigation, sanitation harvesting, relies on using chainsaw teams to mechanically remove attacked trees and reduce densities to less than 100 sq. $\mathrm{ft}$. basal area per acre $(23 \mathrm{sq} . \mathrm{m}$ per ha). However, the effectiveness of this strategy is hindered by the visible effects of an infestation becoming manifest long after a stand has been infected. Thus, to more accurately identify candidate sites prone to a near future attack, one needs "to see the infestation" during the green-attack stage when the beetles make their initial assault, yet the tangible changes to the canopy remain hidden to the naked eye (Coggins 2011).

\subsection{Remote Sensing Methods and Research Objectives}

Advances in remote sensing technology, most notably the ability to detect differences between green-attack trees and non-infected trees with spectral and spatial resolutions fine enough to isolate small patches of infected trees that form the leading edge of an outbreak, can increase the accuracy of targeting stands ripe for mitigation, thereby resulting in more efficient deployments of mitigation measures. Thus far, attack detection research has focused mostly on the visible and Near Infrared (NIR) spectrums where the spectral responses are driven by 
changes in leaf pigment concentrations and internal leaf structure. For example, based on 1:2000 color infrared aerial photographs, Murtha and Wiert (1989) found significantly different spectral responses of green-attacked lodgepole pines in the green and red spectral regions. Using lab spectroscopy, Ahern (1988) reported that the NIR range of 730-760 nm was the best for isolating green-attack trees. Similarly, Gong et al. (1997) and Carter and Knapp (2001) stated that portions of the visible and NIR bands were better for separating damaged trees. Using more expensive airborne hyperspectral images that contain much narrower bands than conventional satellite-based multi-spectral images, Heath (2001) found the best bands for separating green-attacked trees were primarily located in the blue and blue-green regions within the visible spectrum. More recently, Sharma (2007) identified hyperspectral bands in the NIR (993-1094 nm) as the most important ones for distinguishing green-attack. Fassnacht et al. (2014) found that spectral bands in the green-peak $(560 \mathrm{~nm})$, red band $(680 \mathrm{~nm})$, and red $(690 \mathrm{~nm})$ portions to be most effective in distinguishing the green-attack damage when using HyMap hyperspectral imagery. Using similar data, Niemann et al. (2015) located two effective narrow windows in the red band (650-685 nm) and shortwave-infrared band (1145-1210 nm).

Attempts to use high-resolution, but lower cost multispectral satellite imagery, for green-attack monitoring have been limited in part because earlier high-resolution satellites measured only four bands (Red, Green, Blue and NIR). Launched in late 2009 from Vandenberg A.F.B., the WorldView-2 satellite with its eight imaging bands contains narrower and tighter spectral resolutions in the visible and near infrared regions that proved crucial for identifying green-attack trees at $0.5 \mathrm{~m}$ spatial resolution (LandInfo 2017). In one important study, Immitzer and Atzberger (2014) used WorldView-2 satellite imagery to survey early bark beetle damage in Norway spruce trees and obtained a top overall accuracy of $76 \%$. They also noted that the green, yellow, and red bands were most important for separating damage classes.

Currently, no known research in North America has used WorldView-2 data to detect green-attacked trees associated with mountain pine beetle attacks. Therefore, this study aims to examine the potential of WorldView-2 satellite imagery for green-attacked tree detection in the ponderosa pine forest of the Black Hills, USA. In addition, the consequences of long term fire policy, climate change, and the use of remote sensing technology to enhance mitigation are discussed.

\section{Study Site}

\subsection{The Black Hills: Physiography, Vegetation and Climate}

Comprising the eastern most outlier of the Rocky Mountains, the Black Hills were uplifted during the Laramide Orogeny (circa 63-68 MY) and consist of four structural components (Figure 3). First, the crystalline core consists of uplifted granitic plutons and schist formed by contact metamorphism associated with the pre-Cambrian granitic intrusions. The granite and schist forms the core of the Black Hills and mountains such as Harney Peak at 7,242 feet $(2207 \mathrm{~m})$ and Mt Rushmore at 5,725 $(1745 \mathrm{~m})$ are most notable. An uplifted and fractured limestone plateau consisting of Mississippian aged limestone and Pennsylvanian sandstone forms the limestone plateau that peaks at 7,100 feet (Mitchell 2002 and 2007). The Limestone plateau covers much of the western Black Hills as it slopes gently towards the Wyoming state line, but is more eroded on the east side, hence the exposure of granite and schist. Cave complexes formed by solution weathering associated with carbonic and/or sulfuric acids are found throughout the Limestone plateau. Wind Cave National Park and Jewel Cave National Monument, along with a host of other privately-owned caves, serve as examples (Mitchell 2007). A sandstone capped hogback possessing local relief ranging from 250-750 feet (75-230 m) circles the perimeter of the Black Hills with the intervening Red Valley comprised of heavily oxidized shales and possessing a modest elevation of roughly 3,500 feet (1065 m) completes the physiographic scene (Mitchell 2007).

Distributed throughout the Rocky Mountains, the Sierra Nevada and the southern Cascades, the heliophytic Ponderosa pine (Pinus ponderosa) with its aggressive and deep tap root forms the dominant mode of vegetation in the Black Hills (Shepperd and Battaglia 2002). Its dark needle color as seen from a distance gave rise to the name Black Hills (Mitchell 2002). When the U.S. Army entered the Black Hills in 1874 and performed a reconnaissance of resources on what was then Sioux nation territory, the ponderosa pine forest within the crystalline core and limestone plateau occurred in an open park-like setting with modestly forested slopes separated by intervening valleys clothed with lush meadows of grass and forbs (Custer 1874 and Dodge 1876). Indeed, stand densities were such that the cavalry units commanded by Lt Col. Custer and Lt. Dodge moved freely through the forest. The non-forested Red Valley still retains a mixture of short and long prairie grasses because of lower precipitation, higher evaporation, and soils with a high clay content that inhibit water penetration (US Army Corps of Engineers, 1989). Within the higher elevations of the Black Hills north facing slopes often possess white spruce on slopes exceeding 6,000 feet or $1830 \mathrm{~m}$ (Froiland 1990). 
From a climatic perspective, the Black Hills form a "humid island" set amidst the Great Plains where annual water balance deficits are the norm. Precipitation ranges from 30 inches $(760 \mathrm{~mm})$ on the northwestern slopes in the northern Hills to 18-20 inches (460-510 mm) in the southern Hills (Western Regional Climate Center 2016). As with the surrounding Great Plains, precipitation maximum occurs in the spring (May and June) and the inter-annual totals exhibit great fluctuation (coefficients of variation ranging from .51 to .70 ), meaning that very wet blocks of years are often separated by notable stretches of abnormally dry years. These naturally occurring dry periods induce a high amount of plant stress on the native Black Hills forest. Temperatures indicative of a mid-continental location (warm summers and cold winter) characterize the Black Hills. However, elevation attenuates summer temperatures and dew points relative to the surrounding Great Plains, while the wintertime influence of highly modified maritime polar air off the Pacific moderates January minima relative to similar latitudes further east in northern Iowa and southern Minnesota.

\subsection{Importance of the Forest Relative to Cultural Pursuits}

Taken together, the physical landscape sets the stage for a wide variety of socio-economic activities ranging from extractive industries to environmental amenities associated with tourism and recreation, all of which assume a healthy and vibrant eco-system (Mitchell 2002). For example, the ponderosa pine forest supplies raw materials to two sawmills located within the region. Recreation and tourism as exemplified by Mt Rushmore along with Wind Cave National Park and Jewel Cave National Monument, which feature the second and third longest caves in the United States, combine to draw more than 3 million tourists annually. Finally, the historic town of Deadwood with its contemporary revival based on historic preservation, legalized gambling, and a host of eccentric characters dating from the 19th century American West, markets itself successfully within the overall regional milieu of the Black Hills (Mitchell 2008).
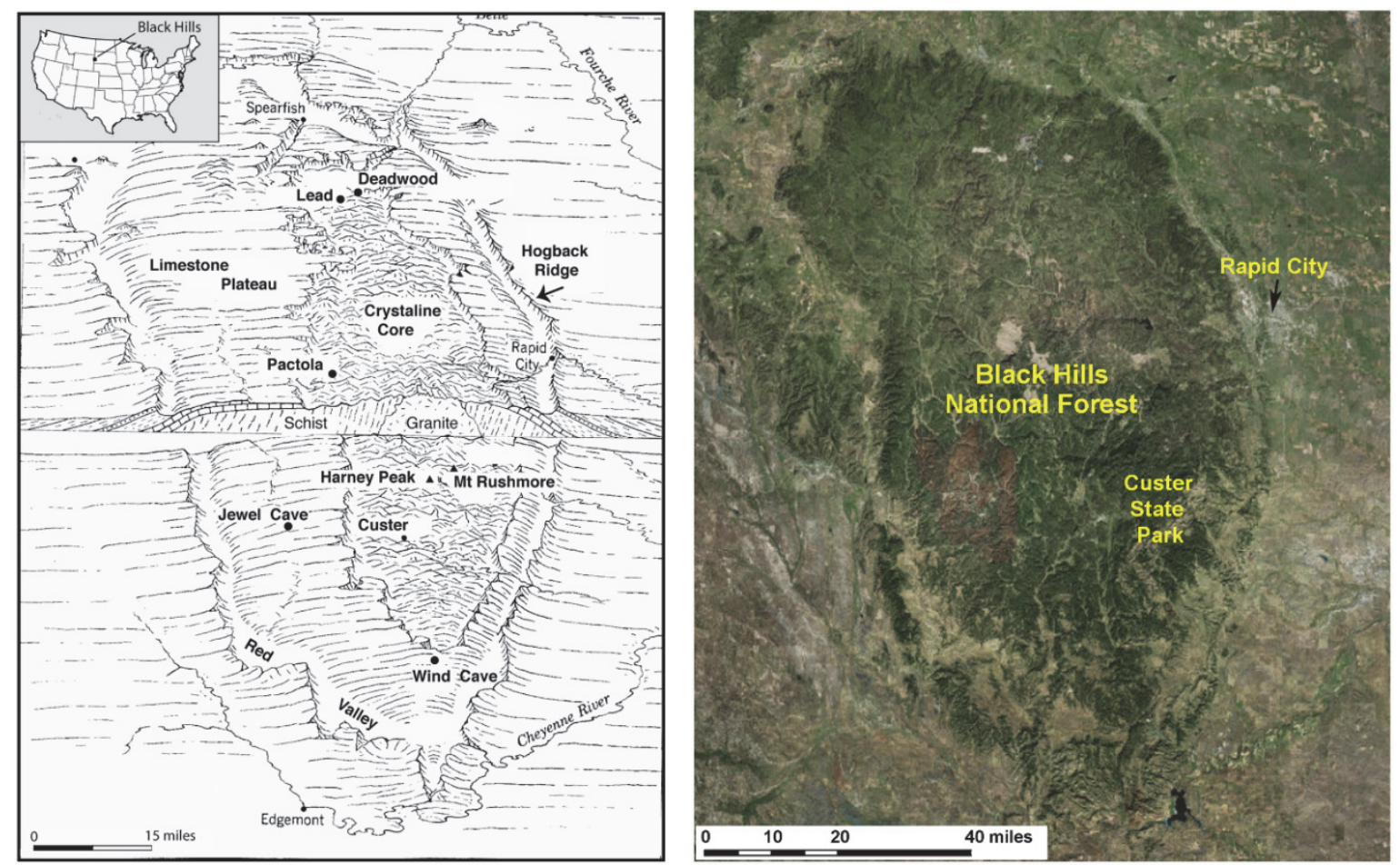

Figure 3. Study site: left panel is a sketch of Black Hills (Thornbury, 1965); right panel shows the Black Hills in a contemporary remote sensing imagery (Image Source: ESRI)

\section{Methods}

\subsection{WorldView-2 Imagery and Pre-Processing}

Two WorldView-2 images with resolutions of $1.85 \mathrm{~m}$ for the multi-spectral bands and $0.5 \mathrm{~m}$ for panchromatic band at nadir were collected on April 9, 2015 with clear skies prevailing. Along with the traditional blue, green, red, and near infrared bands, the WorldView-2 imagery also include 4 additional bands (coastal, yellow, red edge, and a second near infrared band), which may be beneficial for the early detection of beetle damage (Table 2). 
Table 2. Specifications of WorldView-2 Multispectral Bands

\begin{tabular}{ccc}
\hline Band Order & Spectral Band & Spectral Range \\
\hline 1 & Coastal & $400-450 \mathrm{~nm}$ \\
2 & Blue & $450-510 \mathrm{~nm}$ \\
3 & Green & $510-580 \mathrm{~nm}$ \\
4 & Yellow & $585-625 \mathrm{~nm}$ \\
5 & Red & $630-690 \mathrm{~nm}$ \\
6 & Red Edge & $705-745 \mathrm{~nm}$ \\
7 & Near Infrared 1 & $770-895 \mathrm{~nm}$ \\
8 & Near Infrared 2 & $860-1040 \mathrm{~nm}$ \\
\hline
\end{tabular}

The two acquired images covered 9781 ha (4,170 acres) and included portions of the Norbeck Wildlife Refuge, Black Elk Wilderness Area, and Mt. Rushmore National Memorial (Figure 4). Atmospheric correction was performed using the FLAASH 5.3 module with ENVI 5.3 software. Nominal numbers of saturated artifacts were subsequently removed and the images were mosaicked using MosaicPro module within ERDSA Imagine 2015. The multi-spectral WorldView-2 images were fused with the panchromatic image using a Hyperspherical Color Space (HCS) algorithm (Cho et al. 2015), which resulted in a pan-sharpened image for green tree extraction in the next step. Green tree crowns including both green-attack and non-attack trees were extracted from the pan-sharpened WorldView-2 image with Feature Analyst 5.1, using an object-based classifier, because of its higher accuracy relative to a pixel-based approach when using high resolution imagery to classify small vegetative features such as tree crowns (Yu et al. 2006; Immitzer et al. 2012). To preserve the spectral quality of tree crowns, only the original multispectral imagery (not pan-sharpened) was used for spectral data analysis described in section 3.3.

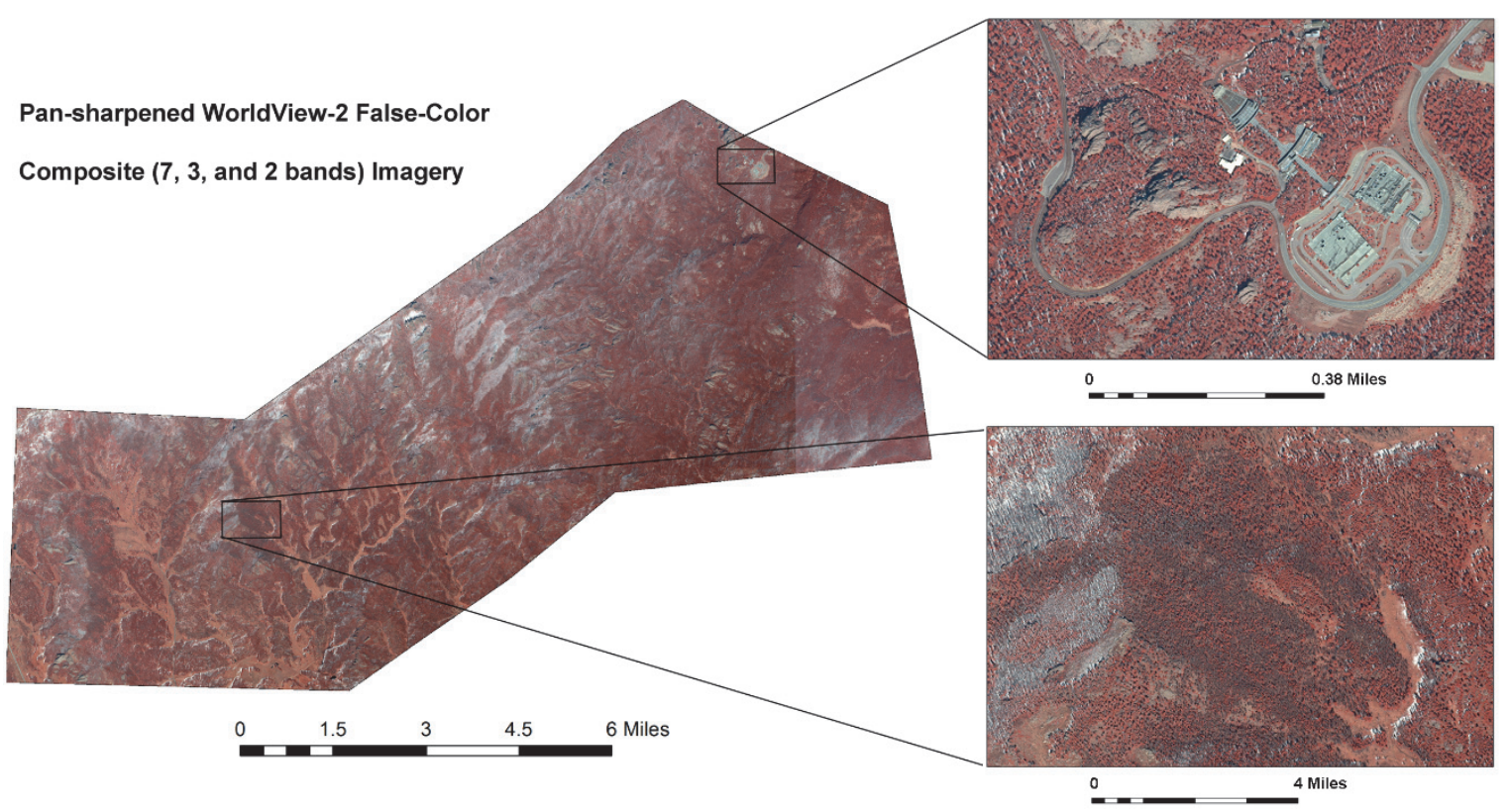

Figure 4. Pan-sharpened WoldView-2 false-color composite (7, 3, and 2 bands) image footprint (left panel) with two close-up views showing Mount Rushmore and surround area (upper-right panel) and ponderosa pine forests located in the southwest part of the study area (bottom-right panel)

\subsection{Field Data Collection and Processing}

Training data were collected on March 7-8 and March 11, 2015 using a Trimble GeoXH GPS unit synched for real-time differential corrections. Clusters of green-attack trees and non-attack trees were sampled. Green-attack trees were selected if they showed signs of a successful beetle attack but had no visual signs of fading in the tree crown. The late winter/early spring acquisition dates were chosen because they allow more time for stress to develop given the region's precipitation maximum of late spring, thereby increasing the probability of obtaining sharper spectral signatures between green-attack and non-attack trees. 
A total of 291 green-attack and 414 non-attack tree crowns were delineated and converted to shapefiles in ArcMap 10.3. These were subsequently used to extract the reflectance values from the multi-spectral WorldView-2 image yielding a total of 4,697 pixels representing green-attack crowns with each polygon (tree crown) averaging 12 pixels. Meanwhile, another 2,626 pixels representing non-attack trees with crown polygons averaging 6 pixels were extracted from the WorldView-2 imagery. The pixel discrepancy (12 vs 6) was likely because of the higher stand densities associated with the green-attack trees and in inclusion of overlapping green-attack crowns in a single polygon (Mullen 2016).

\subsection{Spectral Data Processing and Importance Analysis of the Spectral Variables}

Using the delineated green-attack and non-attack reference polygons, reflectance values were extracted for all eight WorldView-2 spectral bands. Spectral reflectance signatures were created consequently by calculating the mean reflectance values of the green-attack and non-attack tree crowns for each WorldView-2 band. In addition, normalized two-band indices $\left(\right.$ Band $_{i}-$ Band $\left._{\mathrm{j}}\right) /\left(\right.$ Band $_{\mathrm{i}}+$ Band $\left._{\mathrm{j}}\right)$ were created using all possible band combinations, giving a total of 28 indices. Compared to single band reflectance, indices have been shown to be better indicators of damage stress as they combine information from multiple bands and emphasize differences between green-attack and non-attack classes (Immitzer and Atzberger 2015). The normality of the extracted data was assessed using Shaprio-Wilk test $(\mathrm{P}<0.05)$ and normal $\mathrm{Q}-\mathrm{Q}$ plots. Both the 8 spectral bands and the 28 normalized two-band indices, 36 in total, were served as potential predictor variables in the statistical models.

Four statistical approaches were utilized to compare the spectral responses of green-attack and non-attack tree crowns and identify the most important spectral variables for separating classes (Mullen 2016). Details about these statistical approaches are summarized in Table 3. First, the non-parametric Mann-Whitney-U test was selected because the majority of the spectral variables showed a non-normal distribution for both the green-attack and non-attack classes. In addition to significance, the effect size between the two classes were determined by Pearson's correlation coefficient (r) values, with $r$-values greater than $0.1,0.3$, or 0.5 being considered small, moderate, or large, respectively (Cohen 1988). Secondly, a logistic regression (LR) analysis with individual spectral variables iteratively used as predictors was conducted. The LR results were assessed using the leave-one-out cross validation (LOOCV) classification accuracies for each spectral variable. In the third method, the factor structure coefficients calculated as the correlations between a particular variable and the linear discriminant function were estimated. The higher the correlation, the greater the ability of the spectral variable to discriminate classes. Lastly, using a Random Forest (RF) classifier, the mean decrease in accuracy (MDA) statistic for each predictor variable was calculated. A higher MDA indicates a greater importance of the spectral variable in RF classification.

Table 3. Adopted statistical approaches and uses in this study

\begin{tabular}{ll}
\hline Statistical Approaches & Uses \\
\hline Mann-Whitney-U test & $\begin{array}{l}\text { Examine the null hypothesis that there were no significant differences } \\
\text { between the green-attack and non-attack classes using the Pearson's } \\
\text { correlation coefficient values. Effect size used to look at magnitude of } \\
\text { differences. }\end{array}$ \\
Examine the discriminatory power of each of the 36 spectral variable \\
using the leave-one-out cross validation (LOOCV) classification \\
accuracies. \\
Linear Discriminant Analysis (LDA) \\
Evaluate the ability of a spectral variable to discriminate the \\
green-attack and non-attack classes using the factor structure \\
coefficients. \\
Determine the importance of a particular spectral variable in RF \\
classification using the mean decrease in accuracy (MDA) statistic \\
when the variable is left out of the RF classification.
\end{tabular}

\subsection{Green-attack and Non-Attack Classification and Validation}

Classification modeling was performed and examined using three different classification algorithms. Variable groupings used as the inputs consisted of a group using all 36 spectral variables, another grouping using the eight native WorldView-2 bands, and a third grouping selected based on the variable importance indicators. A correlation matrix between the variables was examined for the latter grouping to reduce variable redundancy by 
removing important variables that had high correlations with other important variables. Two-thirds of the sample dataset was split to serve as training data for the classification models and one-third was used for validation purposes. LR, LDA, and RF classification algorithms were applied to classify tree crowns into green-attack and non-attack classes. In particular, LR was chosen because it is robust against violations of assumptions and it allows for categorical binary dependent variable and single predicting variables to be used in the model. LDA classification is a powerful classifier, but is more susceptible to violations to data assumptions. It was included in this study to see if it could handle the non-parametric data. RF classification was chosen because it has shown to be a robust classifier compared to other popular classification algorithms, while providing comparable or better results (Ham et al. 2005; Gislason et al. 2006; Chan and Paelinckx 2008; Rodriguez-Galiano et al. 2012; Immitzer and Atzberger 2014). Performance of these classifiers was compared using both leave-one-out cross-validated accuracies of the training data split and classification accuracies of the validation data split.

\section{Results and Discussion}

\subsection{Spectral Variable Importance}

The mean reflectance values of green-attack trees were higher than non-attack trees in the visible (coastal through red) bands and lower in the red-edge, NIR1, and NIR2 bands (Figure 5). Increased reflectance of green-attack trees within the visible bands might be caused by the decreased absorption by photosynthetically active pigments (Carter and Knapp, 2001), which indicates a severe level of green-attack stage damage as spectral changes in the blue and red spectral regions do not manifest until severe stress and chlorophyll loss has developed (Blackburn, 1998; Carter and Knapp, 2001; Blackburn, 2007; Mullen, 2016). In the visible bands the green-attack class values have greater standard deviations compared to the non-attack class. This is expected because the rates and timing of stress development within attacked trees is highly variable (Wulder et al., 2009).

The green-attack reflectance in the red-edge band was significantly lower than that of non-attack trees. This is in conformity with Ahern's (1988) finding on green-attack lodgepole pines using field hyperspectral data. Furthermore, for green-attack trees, the reflectance in NIR bands were significantly lower, conforming to previous green-attack research using either hyperspectral data (Ahern 1988; Sharma, 2007; Niemann et al., 2015; Immitzer) or WorldView-2 imagery (Atzberger, 2015). The NIR reflectance is mainly affected by the structure of the spongy mesophyll in plants as the NIR radiation penetrates deeper into leaves and interacts primarily with the spongy mesophyll. As stress develops, there is a reduction in the number of refractory surfaces within the spongy mesophyll caused by a reduction in intercellular cavities and air-to-water interfaces (Ceccato et al., 2001); consequently, the NIR spectral reflectance is suppressed.

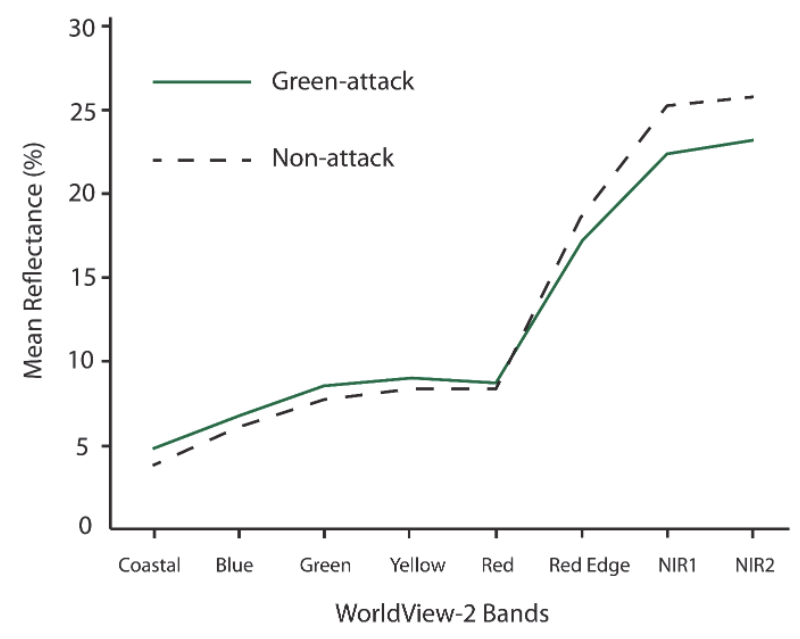

Figure 5. Mean reflectance values of green-attack and non-attack trees in each WorldView-2 band.

A large majority of the classes had a non-parametric distribution for each spectral variable. According to the Mann-Whitney-U test $(\mathrm{df}=1 ; \mathrm{p}<0.05)$, the spectral responses of green-attack trees were significantly different than non-attack trees for all WorldView-2 bands. However, the effect sizes of these spectral differences were small $(0.1<\mathrm{r}<0.3)$, with the greatest differences between the green-attack and non-attack trees found in the NIR1 band followed by the NIR2 band. The normalized two-band index using NIR1 and red edge bands had the greatest magnitude of difference between the two classes. Comparatively, the normalized two-band indices 
utilizing a combination of the NIR1 band and a visible band had higher effect sizes than indices using the NIR2 band or red-edge bands paired with visible bands whereas the indices using two visible bands had non-significant differences between the two classes.

LR classification models using single spectral variables ranged from $57.66 \%$ to $65.54 \%$ accuracies. For the single WorldView-2 band models, the coastal band produced the highest LOOCV accuracy $(63.15 \%)$ while the opposite was the true for the red-edge band. The other visible bands had slightly lower but comparable accuracies to the coastal band. For the models using single normalized two-band indices, the NIR1 and green band index produced a maximum accuracy of $65.54 \%$, and indices using a combination of a NIR band and a visible band had higher accuracies than combinations using two visible bands or two NIR bands.

The LDA analysis also demonstrated that the NIR1 band had the highest correlation with the LDA function, followed by the coastal band, while the red-edge band has the lowest discriminatory power. Normalized 2-band index combinations utilizing one of the NIR bands and the coastal, green, yellow, or red band resulted in better discrimination than indices using two visible band combinations.

The NIR1 band had the highest influence on RF classification. The mean decrease of accuracy (MDA) value dropped 22.83\% when NIR1 was removed from the RF model while other bands had MDAs ranging from 12.61\% to $16.57 \%$. Among the normalized two-band indices, the index using NIR1 and red edge had the highest overall MDA of $27 \%$ while other indices had MDAs ranging from about $4.5 \%$ to $18 \%$.

\subsection{Classification Accuracies of Green-attack and Non-attack}

The selection of high separation and low correlation variables process started with the normalized two-band index using the red edge and NIR1 bands as it had relatively low correlations with other predictor variables but high measures of variable importance. Spectral variables were then added or subtracted in a trial and error manner based on improvements in cross-validated model accuracies until no further improvements could be achieved. As a result, six spectral variables including three normalized two-band indices (red edge-NIR1, yellow-NIR1, and coastal-NIR1) and three individual bands (NIR1, NIR2, and yellow) were selected as the predictors for green-attack and non-attack classification models. The classification results based on this selected grouping of variables were also compared to those results based on classification models using all 36 spectral variables and the eight native WorldView-2 bands as the inputs.

Classification models using all 36 predictor variables as inputs for classification models yielded just slightly higher overall accuracies than the models using the eight native WorldView-2 bands or the selected 6 important variables. The LR classifier yielded the highest overall accuracies in most cases followed by the RF classifier (Table 4).

Table 4. Cross-Validated classification accuracies for each classifier

\begin{tabular}{|c|c|c|c|c|c|c|}
\hline $\begin{array}{l}\text { Predictor } \\
\text { Variables } \\
\text { Used }\end{array}$ & Classifier & $\begin{array}{l}\text { Overall } \\
\text { Accuracy } \\
\text { (\%) }\end{array}$ & $\begin{array}{l}\text { Green-attack } \\
\text { User's } \\
\text { Accuracy } \\
(\%)\end{array}$ & $\begin{array}{l}\text { Non-attack } \\
\text { User's } \\
\text { Accuracy } \\
(\%)\end{array}$ & $\begin{array}{l}\text { Green-attack } \\
\text { Producer's } \\
\text { Accuracy (\%) }\end{array}$ & $\begin{array}{l}\text { Non-attack } \\
\text { Producer's } \\
\text { Accuracy (\%) }\end{array}$ \\
\hline All & LR & 75.96 & 74.25 & 76.9 & 63.92 & 84.42 \\
\hline spectral & LDA & 68.94 & 55.67 & 78.26 & 64.29 & 78.26 \\
\hline variables & $\mathrm{RF}$ & 73.19 & 59.79 & 82.61 & 70.73 & 74.51 \\
\hline WorldView-2 & LR & 69.79 & 67.81 & 70.68 & 51.03 & 82.97 \\
\hline \multirow[t]{2}{*}{ bands } & LDA & 67.45 & 46.91 & 81.88 & 64.54 & 68.69 \\
\hline & $\mathrm{RF}$ & 72.13 & 58.76 & 81.52 & 69.09 & 73.77 \\
\hline Selected & LR & 72.34 & 71.33 & 72.81 & 55.15 & 84.42 \\
\hline important & LDA & 71.28 & 51.55 & 85.14 & 70.92 & 71.43 \\
\hline variables & $\mathrm{RF}$ & 72.13 & 59.79 & 80.8 & 68.64 & 74.09 \\
\hline
\end{tabular}

When performance was assessed using the validation data-split, the accuracies were generally $2-5 \%$ lower compared to the cross-validated accuracies (Table 5). Observed classification accuracies of the data-split were more closely aligned between the three classifiers for each grouping compared to the cross-validated accuracies (Table 5). The RF classifier based on the eight native WorldView-2 bands produced the best performing model (70.64\%), followed by the RF classifier (70.21\%) based on the selected spectral variables. The LR and LDA methods had comparable performance for both cases. 
Table 5. Classification accuracies tested using an independent data-split for each classifier.

\begin{tabular}{|c|c|c|c|c|c|c|}
\hline $\begin{array}{l}\text { Predictor } \\
\text { Variables } \\
\text { Used }\end{array}$ & Classifier & $\begin{array}{l}\text { Overall } \\
\text { Accuracy } \\
(\%)\end{array}$ & $\begin{array}{l}\text { Green-attack } \\
\text { User's } \\
\text { Accuracy } \\
(\%)\end{array}$ & $\begin{array}{l}\text { Non-attack } \\
\text { User's } \\
\text { Accuracy } \\
(\%) \\
\end{array}$ & $\begin{array}{l}\text { Green-attack } \\
\text { Producer's } \\
\text { Accuracy (\%) }\end{array}$ & $\begin{array}{l}\text { Non-attack } \\
\text { Producer's } \\
\text { Accuracy (\%) }\end{array}$ \\
\hline All & LR & 69.79 & 66.25 & 71.61 & 54.64 & 80.43 \\
\hline spectral & LDA & 69.36 & 50.52 & 82.61 & 67.12 & 70.37 \\
\hline variables & RF & 68.51 & 59.79 & 74.64 & 62.37 & 72.54 \\
\hline \multirow{3}{*}{$\begin{array}{l}\text { WorldView-2 } \\
\text { bands }\end{array}$} & LR & 66.38 & 62.86 & 67.88 & 45.36 & 81.16 \\
\hline & LDA & 67.76 & 44.33 & 84.06 & 66.15 & 68.24 \\
\hline & RF & 70.64 & 59.79 & 78.26 & 65.91 & 73.47 \\
\hline Selected & LR & 66.81 & 62.67 & 68.75 & 48.45 & 62.67 \\
\hline important & LDA & 67.23 & 46.39 & 81.88 & 64.29 & 68.48 \\
\hline variables & $\mathrm{RF}$ & 70.21 & 58.76 & 78.26 & 65.52 & 72.97 \\
\hline
\end{tabular}

Lower user's and producer's accuracies for green-attack class than the non-attack class were observed in both tables, which are likely attributed to large within-class variance and spectral confusion with non-attack trees. The LR classifiers yielded higher user's accuracies for non-attack class in most of the cases, followed by the RF models. However, the LDA classifier achieved the highest producer's accuracies of green-attack class for most of the cases. Compared to the parametric LDA classifier, the LR and RF methods are more robust against non-normality and multicollinearity; therefore, they outperformed the LDA classification in general. Moreover, RF models are less prone to overfitting models, especially with larger numbers of predictor variables (Brieman 2001; Liaw and Wiener 2002).

\section{Conclusions and Lessons Learned}

Our research indicates that the NIR1 band of the WorldView-2 imagery is a key dataset for green-attack detection. Despite substantial overlap in spectral response variability between the green-attack and non-attack classes, WorldView-2 imagery and the methods analyzed in this study show some promise towards the discrimination of green-attack damage, with a highest overall accuracy of $70.64 \%$. Such accuracy is comparable to Immitzer and Atzberger's (2014) spruce beetle green-attack study and to previous mountain pine beetle green-attack studies using costlier, but higher spectral resolution, airborne hyperspectral data (Health 2001; Fassnacht et al. 2014). Although, this rating is far less than 100\%, it also comprises a major advance over earlier remote sensing methods that focused on the detection of red-attack damage and were inhibited by coarseness of resolution, both spatially and in terms of isolating narrow ranges of spectral reflectance. Similarly, our results provide a more accurate and systematic means for managing mitigation during an epidemic and can form a baseline dataset from which field-based decisions by forestry officials can be made.

Geospatial technology is dynamic and evolves quickly. As such, we believe over the next ten years that models based on satellite data and quantitative analyses will become increasingly more accurate and be widely deployed by forest resource agencies to more effectively mitigate epidemics of mountain pine beetles. However, technology is not everything and adopting policies that minimize or even pre-empt the need to use such technology within the context of an epidemic are also important.

Consequently, recurring short-term mitigations such as prescribed burning or mechanical thinning with chainsaw crews to pre-empt the long-term effects of fire suppression policies within the context of a climate prone to high inter-annual variations of precipitation comprises an important lesson based on the Black Hills experience. This situation applies to other areas of the West dominated by ponderosa pines with the Sierra Nevada and southern Cascades of California being a prime example. This finding is magnified by the climate change factor of less severe daily minimum winter temperatures (defined as $\leq-20^{\circ} \mathrm{F} /-29^{\circ} \mathrm{C}$ ) in December and January as experienced in South Dakota's Black Hills. Indeed, the specific need to thin ponderosa forests to stand densities less than 100 sq. $\mathrm{ft}$. of basal area per acre ( 23 sq. $\mathrm{m}$ per ha) is paramount, especially in a forest regime where three to five ground fires per 100 years were the natural norm prior to Euro-American settlement. Although such mitigations involve on-going expenditures of public funds and accentuated human intervention, they must be measured against the costs associated with the devastation of vast tracts of timber, its elevated fire danger, and the aesthetical impact upon recreational pursuits in the National Forests of the Western United States wrought by a mountain pine beetle epidemic. Such costs borne of a pine beetle epidemic are often spatially concentrated and have a long-term environmental effect on a given region with the Black Hills serving as a prime example. 


\section{Acknowledgments}

We wish to thank Marvin Auchtenburg of the U.S. National Park Service, and Gary Brundige of the South Dakota Dept. of Game, Fish and Parks, and Dr. Brittany Smith of Minnesota State University, Mankato for their time and information. We also thank Mary Dooley, James and Betty Goff and Dean Barry Ries of the College of Graduate Studies and Research at Minnesota State University, Mankato for their financial support for this research.

\section{References}

Ahern, F. J. (1988). The Effects of Bark Beetle Stress on the Foliar Spectral Reflectance of Lodgepole Pine. International Journal of Remote Sensing, 9(9), 1451-1468. https://doi.org/10.1080/01431168808954952

Auchtenburg, M. (2016). Personal communication. Mr. Auchtenburg is an Interpretative Ranger at Mt. Rushmore National Memorial.

Ballard, R., Walsh, M., \& Cole, W. (1984). The Penetration and Growth of Blue-Stain Fungi in sapwood of Lodgepole pine attacked by Mountain Pine beetle. Canadian Journal of Botany, 62, 1724-1729. https://doi.org/10.1139/b84-233

Bentz, B., Logan, J., \& Amman, G. (1991). Temperature Dependent Development of the Mountain Pine Beetle. The Canadian Entomologist, 123(5), 1083-1094. https://doi.org/10.4039/Ent1231083-5

Blackburn, G. A. (1998). Spectral indices for estimating photosynthetic pigment concentrations: A test using senescent tree leaves. International Journal of Remote Sensing, 19(4), 657-675. https://doi.org/10.1080/014311698215919

Blackburn, G. A. (2007). Hyperspectral remote sensing of plant pigments. Journal of Experimental Botany, 58(4), 855-867. https://doi.org/10.1093/jxb/erl123

Breiman, L. (2001). Random Forests. Machine Learning, 45(1), 5-32.

Brown. P., \& Sieg, C. (1996). Fire History in Interior Ponderosa Pine communities in the Black Hills, South Dakota, USA. Journal of Wildfire, 6(3), 97-105. https://doi.org/10.1071/WF9960097

Brundige. G. (2011). personal communication. Mr. Brundige is the Resource Program Director at Custer State Park, Custer, S.D.

Carter, G. A., \& Knapp, A. K. (2001). Leaf Optical Properties in Higher Plants: Linking Spectral Characteristics to Stress and Chlorophyll Concentration. American Journal of Botany, 88(4), 677-84. https://doi.org/10.2307/2657068

Ceccato, P., Flasse, S., Tarantola, S., Jacquemoud, S., \& Grégoire, J. M. (2001). Detecting vegetation leaf water content using reflectance in the optical domain. Remote Sensing of Environment, 77(1), 22-33. https://doi.org/10.1016/S0034-4257(01)00191-2

Chan, J. C. W., \& Paelinckx, D. (2008). Evaluation of Random Forest and Adaboost tree based ensemble classification and spectral band selection for ecotope mapping using airborne hyperspectral imagery. Remote Sensing of Environment, 112(6), 2999-3011. https://doi.org/10.1016/j.rse.2008.02.011

Cho, M. A., Malahlela, O., \& Ramoelo, A. (2015). Assessing the Utility of WorldView-2 Imagery for Tree Species Mapping in South African Subtropical Humid Forest the Conservation Implications. International Journal of Applied Earth Observation and Geoinformation, 38, 349-357. https://doi.org/10.1016/j.jag.2015.01.015

Coeur Mining. (2016). Visit to Wharf Mine and personal communication from Brad Stock, Chief Geologist. Lead S.D.

Coggins, S. (2011). Comparing the Impacts of Mitigation and non-Mitigation on Mountain Pine Beetle $\begin{array}{llll}\text { Populations. Journal of Environmental Management, } & \text { 92(1), }\end{array}$ http://dx.doi.org/10.1016/j.jenvman.2010.08.016

Cohen, J. (1988). Statistical Power Analysis for the Behavioral Sciences (2nd ed.), New York: Academic Press.

Custer. G. A. Lt Col. USA. (1874). Letter to Commanding Officer General Terry. Cited in Calhoun, J. Lt. USA. With Custer in '74. Provo. Brigham Young Press.

Dodge, R. I. Lt. Col. USA. (1876). The Black Hills. Reprinted by Pelican Publishing, Gretna LA.

Fassnacht, F. E., Latifi, H., Ghosh, A., Joshi, P. K., \& Kock, B. (2014). Assessing the potential of hyperspectral 
imagery to map bark beetle-induced tree mortality. Remote Sensing of Environment, 140, 533-548. https://doi.org/10.1016/j.rse.2013.09.014

Froiland, S. (1990). Natural History of the Black Hills and Badlands. Sioux Falls: Center for Western Studies.

Gislason, P. O., Benediktsson, J. A., \& Sveinsson, J. R. (2006). Random Forests for land cover classification. Pattern Recognition Letters, 27, 294-300. https://doi.org/10.1016/j.patrec.2005.08.011

Gong, P. (1997). Conifer species recognition: An exploratory analysis of in situ hyperspectral data. Remote Sensing of Environment, 62(2), 189-200. https://doi.org/10.1016/S0034-4257(97)00094-1

Graham, R., Asherin, L., Battaglia, M., Jain, B., \& Mata, T. (2016). Mountain Pine Beetle: A Century of Knowledge, Control Attempts and Impacts Central to the Black Hills. U.S. Forest Service, Rocky Mountain Forest and Plains Experiment Station, Ft. Collins, CO.

Ham, J., Chen, Y., Crawford, M. M., \& Ghosh, J. (2005). Investigation of the random forest framework for classification of hyperspectral data. IEEE Transactions on Geoscience and Remote Sensing, 43(3), 492-501. https://doi.org/10.1109/TGRS.2004.842481

Heath, J. (2001). The detection of mountain pine beetle green attacked lodgepole pine using compact airborne spectrographsimager (CASI). M.Sc. Thesis, Faculty of Forestry, The University of British Columbia, p. 72.

Immitzer, M., \& Atzberger, C. (2014). Early Detection of Bark Beetle Infestation in Norway Spruce (Picea abies, L.) using WorldView-2 Data, Photogrammetrie, Fernerkundung, Geoinformation, 5, 351-367. https://doi.org/10.1127/1432-8364/2014/0229

Immitzer, M., Atzberger, C., \& Koukal, T. (2012). Tree Species Classification with Random Forest Using Very High Spatial Resolution 8-band WorldView-2 Satellite Data. Remote Sensing, 4(9), 2661-2693. https://doi.org/10.3390/rs4092661

Landinfo. (2017). WolrdView-2 50cm High Resolution Satellite Imagery. Retrieved May 23, 2017, from http://www.landinfo.com/WorldView2.htm

Letherman, D. A., Aguayo, I., \& Mehall, T. M. (2007). Mountain Pine Beetle Fact Sheet. Colorado State University, 5, 528 .

Liaw, A., \& Wiener, M. (2002). Classification and Regression by Random Forest. R News, 2/3, 18-22.

Mitchell, M. (2002). The Black Hills: Sketches of a Western Landscape. Focus on Geography, 46(4), 22-28. https://doi.org/10.1111/j.1949-8535.2002.tb00023.x

Mitchell, M. (2007). Geographic Wonders: wind Cave and Jewel Cave. Geographiche Rundschau, 3(4), 26-33.

Mitchell, M. (2008). Deadwood, South Dakota: Place and Setting Combine with Gambling and Historic Preservation. Focus on Geography, 51(2), 26-33. https://doi.org/10.1111/j.1949-8535.2008.tb00223.x/full

Mitchell, M., \& Yuan, F. (2010). Assessing Forest Fire Vegetation Recovery in the Black Hills, South Dakota. GIScience and Remote Sensing, 47(2), 276-299. https://doi.org/10.2747/1548-1603.47.2.276

Mullen, K. (2016). Early Detection of Mountain Pine Beetle Damage in Ponderosa Pine Forests of the Black Hills Using Hyperspectral and World View-2 Data. M.S. Thesis. Minnesota State University, Mankato.

Murtha, P. A., \& Wiart, R. J. (1989). PC-based Digital Analysis of Mountain Pine Beetle Current-Attacked and Non-Attacked Lodgepole Pine. Canadian Journal of Remote Sensing, 15(1), 70-79. https://doi.org/10.1080/07038992.1987.10855112

Niemann, K. O., Quinn, G., Stephen, R., Visintini, F., \& Parton, D. (2015). Hyperspectral Remote Sensing of Mountain Pine Beetle with an Emphasis on Previsual Assessment. Canadian Journal of Remote Sensing, 41(3), 191-202. https://doi.org/10.1080/07038992.2015.1065707

Rodriguez-Galiano, V. F., Ghimire, B., Rogan, J., Chica-Olmo, M., \& Rigol-Sanchez, J. P. (2012). An assessment of the effectiveness of a random forest classifier for land-cover classification. ISPRS Journal of Photogrammetry and Remote Sensing, 67, 93-104. https://doi.org/10.1016/j.isprsjprs.2011.11.002

Saffranik, L., \& Carroll, A. (2006). The Biology and Epidemiology of the Mountain Pine Beetle in Pine Forests, in Safranik. L., and B. Wilson. The Mountain Pine Beetle: A Synthesis of Its Biology, Management and Impacts on Lodgepole Pine. Victoria, B.C. Canadian Forest Service, 3-66.

Schmid, J., \& Mata, S. (1992). Stand Density and Mountain Pine Beetle Caused Tree Mortality in Ponderosa Pine Stands. U.S. Forest Service, Rocky Mountain Forest and Plains Experiment Station, Ft. Collins, CO. 
Schmid, J., \& Mata, S. (2005). Mountain Pine Beetle caused Tree Mortality in Partially Cut Plots Surrounded by Unmanaged Lands. U.S. Forest Service, Rocky Mountain Forest and Plains Experiment Station, Ft. Collins, $\mathrm{CO}$.

Sharma, R. (2007). Using multispectral and hyperspectral satellite data for the early detection of mountain pine beetle damage. Ph.D. dissertation, Faculty of Forestry, The University of British Columbia.

Shepperd, W., \& Battagalia, M. (2002). Ecology, Silverculture and Management of Black Hills Ponderosa Pine. U.S. Forest Service, Rocky Mountain Research Station, General Technical Report RMRS-GTR-97. Ft. Collins, CO.

Thornbury, W. (1965). Regional Geomorphology of the United States. New York, Wiley.

U.S. Army Corps of Engineers. (1989). Geographic Resources Analysis Support System. Spearfish Database. Soils and Soils $\mathrm{K}$ factor coverages.

U.S. Department of Agriculture. (2016). Forest Service Health Protection, 2016: Mountain Pine Beetle Summary. Retrieved October 17, 2016, from http://foresthealth.fs.usda.gov/portal/PestSummary/DamageSummary.

U.S. Forest Service. (2010). Topic: Mountain Pine Beetle in the Black Hills and Control Methods for Single Trees. Retrieved October 20, 2016, from at http://www.beatthebeetles.com/docs/mpbcontrolmethods4.pdf

Western Regional Climate Data Center. (2016). Climate Data on Temperature and Precipitation for Pactola Dam, Lead, Mt Rushmore and Custer South Dakota. Retrieved December 2016, from http://www.wrcc.dri.edu/cgi-bin/cliF302010.pl?sd2087

Wulder, M. A., White, J. C., Carroll, A. L., \& Coops, N. C. (2009). Challenges for the operational detection of mountain pine beetle green attack with remote sensing. The Forestry Chronicle, 85(1), 32-38.

Wulder. M., Dymond.C, White. J., Leckie. D., \& Carroll, D. (2006). Surveying Mountain Pine Beetle Damage of Forests: A Review of Remote Sensing Opportunities. Forest Ecology and Management, 221(1) 27-41. https://doi.org/10.1016/j.foreco.2005.09.021

Yu, Q., Gong, P., Clinton, N., Biging, G., Kelly, M., \& Schirokauer. D. (2006). Object-based Detailed Vegetation Classification with Airborne High Spatial Resolution Remote Sensing Imagery. Photogrammetric Engineering \& Remote Sensing, 72(7), 799-811. https://doi.org/10.14358/PERS.72.7.799

\section{Copyrights}

Copyright for this article is retained by the author(s), with first publication rights granted to the journal.

This is an open-access article distributed under the terms and conditions of the Creative Commons Attribution license (http://creativecommons.org/licenses/by/4.0/). 